\title{
Physical-Recreational Games to Increase the Participation of Children in the Recreational Activities of the Bengochea District
}

\author{
Rosa de la Cruz Hernández Moya* and Ernesto Pacheco Rodríguez \\ Universidad Central "Marta Abreu" de Las Villas, Facultad de Cultura Física, Cuba \\ *Corresponding author: Rosa de la Cruz Hernández Moya, Universidad Central "Marta Abreu” de Las Villas, Facultad de \\ Cultura Física. Código, Cuba
}

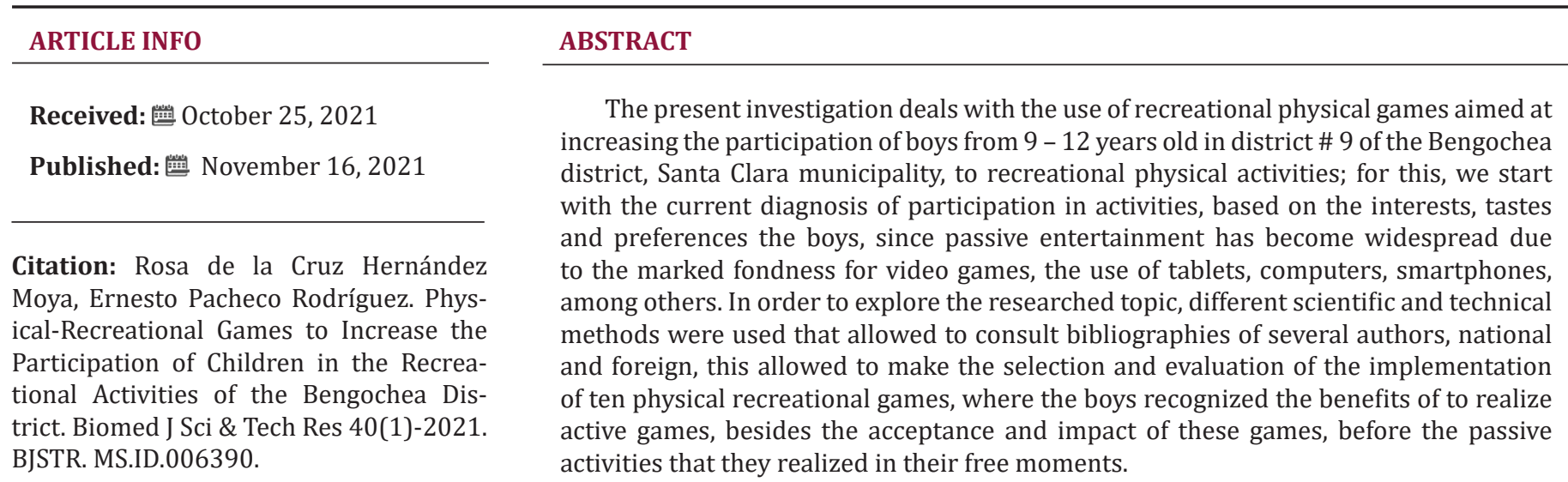

Keywords: Recreational Physical Games; Participation; Recreational Activities

\section{Introduction}

Recreation must serve to sow knowledge, to promote spiritual values such as solidarity and a sense of unity among people. Several researchers at national and international level have addressed the subject making contributions to recreation in which they stand out: (Sosa, 2000; Perez, 2003; Waichman, 2009; Domínguez, 2018) [1-4], among others. In a general sense, everyone considers that Recreation works to teach, educate and raise the quality of life of the community in an organized and harmonious way, thus promoting the achievement of greater cultural, political and social development.

According to the studies carried out by Sosa from the 90s to the present about Physical Recreation, and of which these authors fully agree on the validity it has when it states in the (2000) that:

1. Physical Recreation is the set of physical activities defined by the physical recreational reasons that constitute a subsystem of Recreation and is part of the physical culture of the population with emphasis on active rest, health, the creation of motor habits, fun and creative individual development. This type of Recreation is characterized by a certain level of motor skills, which generates a high level of recreational physical prominence (p. 87).

The present work has as background the research of the authors Vilaú, et al. [5-8]. The aforementioned research allows to reinforce the idea of the work that can be developed in terms of Recreation in the communities, aimed at children, due to the little motivation and the lack of participation on the part of these in the physical-recreational activities in the communities, since in the vast majority of the planned activities the same games are executed, without looking for other alternatives or variants that stimulate the participation of infants, based on their tastes, interests and needs. In the observations made in the community, the interviews with the 
children, relatives and neighbors of the community, the following probability situation could be appreciated: limited participation in the physical-recreational activities of the children of $9-12$ years of the circumscription \# 9 of the Bengochea Distribution, of the municipality of Santa Clara. The above allows us to formulate the following scientific problem: How to increase the participation in physical-recreational activities of children aged $9-12$ years of the district \# 9 of the Bengochea Distribution, of the municipality of Santa Clara?

For the development of the research, the following system of objectives is proposed:

1. Diagnose the initial state of participation, tastes and preferences to physical-recreational activities of children from 9 - 12 years of age in district \# 9 of the Bengochea Distribution, in the municipality of Santa Clara.

2. Select physical-recreational games to increase the participation in the physical-recreational activities of children from $9-12$ years of age in constituency \#9 of the Bengochea Distribution, in the municipality of Santa Clara.

3. To assess the participation in the physical-recreational activities of the children of $9-12$ years of the circumscription \# 9, from the application of the physical-recreational games.

The importance of this research is to promote that the game is an essential means within recreation, provided that it is known at what stage it is most important to play and what are the purposes of the game, such as: teaching, culturizing, transcending, distracting, investigating, developing, generating, creating; everything depends on the form, the type of game and the attitude that is adopted before the essential activity of the playful. According to the diagnosis made and the practical experience of the authors, it is evident that most of the children aged $9-12$ years of the constituency \# 9 of the Bengochea Distribution, are limited to participating in physicalrecreational activities, since those that are carried out are not of their interest or preference, since passive entertainment has become widespread due to the marked fondness for video games, the use of new information and communication technologies, such as computers, Xbox, tablets, smartphones, and other electronic equipment, increasingly inducing new generations to addiction to cyber games, which is counterproductive with the needs of the physical and psychological development of this age group.

\section{Methodology Used}

For the development of the research, the authors relied on the concepts issued by Hernández et al. [9], using methods and techniques, which allowed to obtain an accurate information of the problem raised, of the theoretical level, the analytical-synthetic; inductive-deductive that were applied for the theoreticalmethodological foundations of recreation, physical recreation and games, as well as to carry out an objective study of the participation of children in physical and recreational activities, in addition to the preparation of the professional of Physical Culture and other managers. The research involves a first population composed of 12 girls and 17 boys aged $9-12$ years, a second population composed of 3 professionals of the Physical Culture of the Sports Combined "Martyrs of Barbados" and 15 subjects of the community, 11 relatives and 4 neighbors, all belonging to the constituency \# 9 of the Bengochea Distribution, Santa Clara municipality.

\section{Analysis of the Results and Discussion}

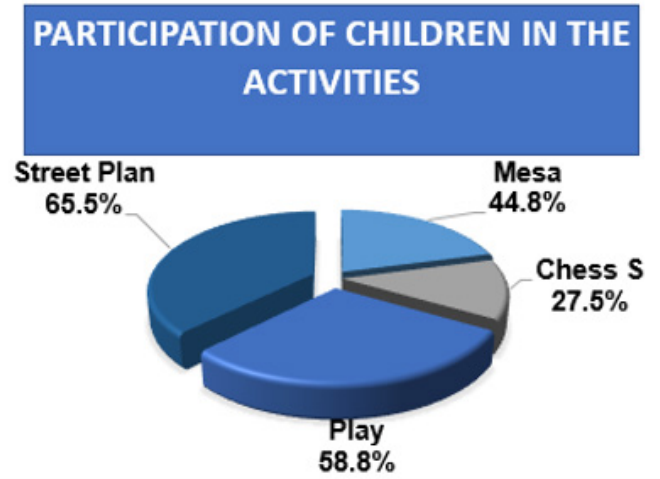

Figure 1.

Physical-recreational activities such as board games, simultaneous chess, to play and street plan were observed, carried out in the district \# 9, of the Bengochea Distribution for 8 months from which the following results were obtained: The relatives and neighbors of the community felt concerned about how the children used their free time in activities not proper to their age, which was interfering in their bio-psycho-pedagogical and social development, since a systematization was not achieved in the physical-recreational activities that were carried out by the physical recreation teachers. It should be noted that disclosure does not disclose in advance all activities, which can influence the poor participation of children in the activities being carried out. As for the preparation of recreation teachers, although they have mastery of their work, it was found that not everyone prepares for the realization of the activities, nor do they carry out actions to increase the participation of children in recreational activities, since sometimes they showed demotivation, lack of creativity and interest in the search for alternatives or new games for the execution of the activities. In the aspect related to the participation of children in recreational activities in a general sense, Mal was evaluated; in the board games, only 5 girls and 8 boys attended for $44.8 \%$. Regarding the simultaneous chess, 3 girls and 5 boys participated, for $27.5 \%$. The highest participation was 
observed in the "A jugar", with 7 girls and 10 boys, which represents $58.6 \%$ and in the Street Plan 9 girls and 10 boys were present, which represented $65.5 \%$ (Figure 1).

The evaluation of this aspect with respect to participation was influenced by the poor attendance of children aged 9-12 years to recreational physical activities, as well as the organization of the area for the development of activities, since the necessary conditions were not created in terms of the use and creativity of means and implements, the area for the execution of the activities was not correctly delimited, in addition there were no varied offers, since generally the planned activities were carried out and the space was not used to insert other small, recreational, traditional and / or pre-sports games. When applying the interview, it was possible to know that there are 6 children (20.6\%) whose reasons are related to going to the cinema or the park with their friends, 5 $(17.2 \%)$ watch tv, $8(27.5 \%)$ use new technologies to play on the computer or Xbox, as well as connect on social networks with their smartphones, only 10 (34.4\%) prefer to participate in physicalrecreational activities. The 4 neighbors of the community that represents $26.6 \%$, raised that currently children from $9-12$ have a marked interest in new technologies and the use of social networks, since in the area where they live there is a wifi antenna, in terms of support and realization of them to the recreational activities that are planned, participation may be better, in order to avoid other activities, which are not appropriate for their age, nor are they beneficial for the development of children, since sometimes it causes in some children, manifestations of inappropriate behaviors.

The relatives who represent $72.7 \%$ stated that they like their children to perform recreational activities, as well as games and sports, but that currently they do not participate for reasons of time, although they prefer to have their children quiet at home watching television or making use of new technologies, since they are motivated by electronic games or being connected in social networks, since in the area there is wifi and on the other hand 3 of the relatives who represent $27.2 \%$ do not like to pressure their children, and try to support them in what they like to do, referring to the activities of the age. In the results of the interviews conducted with the children, relatives, neighbors and recreation teachers, it was found that they had poor participation in the physicalrecreational activities that were offered, so that the children participated in other activities, many of which are not appropriate for their age, demonstrating the addiction to electronic games and social networks, this motivated the search and selection of several physical-recreational games that contributed to the increase in participation in the activities of children from $9-12$ years old from the constituency \# 9 of the Bengochea Distribution of the municipality of Santa Clara.

For the selection of traditional games, the general characteristics according to Watson (2008) [10] were taken into account, which are:

a) They are played by children for the sheer pleasure of playing, who decide when, where and how to play.

b) Respond to children's basic needs.

c) The rules are easy to understand, memorize and comply with, but they are also negotiable since they can be varied.

d) They do not require many materials and the necessary ones are not very expensive.

e) They are simple and easy to share with other players.

f) They can be practiced at any time and place.

g) They arise for a season, disappear and then reappear.

Some games are practiced more in winter times, since they involve greater physical and body movement, while others arise in times of greater heat (summer).

\section{Below are 9 of the 15 Physical-Recreational Games that Were Put into Practice}

\section{The Three Towers}

A. Development: At the signal of the teacher the participants formed in teams, but in trios, run to the cone, which is at a distance of 6 meters, then they enter a ring that take it to the waist and move to the little flag that is placed another 6 meters to which they turn, until they reach the cone where they leave the hoop and run in a trio to the finish line to give the exit to the next trio of the team, which will perform the same action.

B. Rules: The race is held in trios; no child can get ahead.

\section{Balloon Up and Down}

A. Materials: Balloons, water Organization: rows in teams Development: the participants with their legs apart, will be placed one after the other and at a small distance, at the signal of the teacher the first of each row will hold a balloon full of water and pass it over the head and the second will pass it underneath, until reaching the last child who will come running until the beginning of the row and will perform the same action until everyone has executed it.

B. Rules: Always the first of each row passes the balloon overhead and prevent it from breaking. 


\section{Wall, Hunter and Deer}

\section{A. Materials:}

i. None Organization: Rows in teams Development: they begin by telling them that the wall is when the flexed arms are placed in front and the palms of the hands are open, the hunter is when one of the arms extends to the front reseling a rifle and the deer is when the hands are placed on the head making horns, the wall for the bullet fired by the hunter, the deer jumps the wall and the bullet kills the deer, then the teams are formed, these internally will agree and choose what action they will perform, then they are placed in rows facing each other, but on their backs, and to the sound of the teacher's whistle the participants turn straight representing the wall, the hunter or deer who will accumulate points.

B. Rules: Only one action can be represented by the participants. If a team participant makes a mistake and does not do the action of the rest of his teammates, the team loses. The team that manages to accumulate the most points win.

C. Variants: It can be done with other animals or objects such as stone, paper and pencil.

\section{Three-Foot Race}

A. Materials: Rope. Organization: duos in teams Development: the participants in pairs, will be placed next to each other and will tie their ankles with a rope, and at the signal of the teacher they will run to the indicated distance, they will turn the cone and when they reach the finish line they will release the rope of the ankles and give it to the other couple.

B. Rules: They must run harmoniously without letting go. Teammates can help tie the rope. The team that finishes first and does it best wins.

C. Variant: You can divide the teams in two and place themselves in front of each other and do it in relay.

\section{Transport of Objects in Duos}

A. Materials: Cones, bowling, swiss, balls, flags. Organization: teams, duos Development: at the signal of the teacher the first pairs of children will move through the area carrying three different objects with their chests, but without using their hands, when they reach the finish line, they must pass the objects to another couple, and so on until they have all finished.

B. Rules: Couples cannot use their hands but can be helped by another participant. If an object falls it must be picked up and then continue the game. The team that first finishes having transported the objects without touching it wins.
C. Variant: You can transport the objects head-to-head, back to back, hip to hip, etc.

\section{The Basket}

A. Materials: Box (basket), cards Organization: rows in teams Development: the participants will be seated behind a starting line, at the signal of the teacher the first of each team will run to the basket and inside this there will be several cards with different syllables where the players upon arrival will have to form a word and say which one was the one that formed, because another player can not recreate it.

B. Rules: They must go out to the teacher's signal. Players cannot form the same word twice. The team that has formed the most words win.

C. Variants: The teacher can say the word for the participants to form and the one who first creates it wins, it can also be done with mathematical operations.

\section{To Fill the Knob}

A. Materials: Buckets, knobs, disposable cups, water, flags Organization: rows in teams Development: the teams formed behind the starting line will have a plastic knob and at a distance a bucket with water is placed with a disposable glass inside, at the signal of the teacher the first participants run out with the knob, when they reach the place where the bucket is, they pour a glass of water and run back to give exit to the next child, so on until they all culminate.

B. Rules: The team with the most water on the knob wins. Participants must exit behind the starting line. Only one glass of water per player can be poured into the knob.

C. Variants: It can be executed by measuring time and players can repeat as many times as possible until the time given by the teacher is consumed.

\section{Rock, Paper and Scissors in Motion}

A. Material: Rings, chalk Organization: rows Development: they are placed in teams by rows facing each other, and at a distance of 20 meters hoops are placed or drawn with chalk, one after the other, changing direction every four implements. At the teacher's signal the first students jump out on each hoop, as quickly as possible and when confronted by the participants say: "Rock, paper or scissors. One, two, three" each take out what they want. The participant who loses goes to the opposing team and the other continues, because from the other team another child must leave very quickly to prevent him from reaching the goal and challenge him with rock, paper or scissors, and so on everyone must perform the game until it ends. 
B. Rules: The stone beats the scissors, the scissors the paper and the paper the stone. To leave a participant must wait for their child to lose or reach the finish line. You should jump on the hoops with both legs together.

\section{The Chain with Rings}

A. Materials: Rings Organization: rows or circles Development: two teams are formed and the participants hold hands forming a row or circle, between two children a ring is placed and at the signal of the teacher they must pass the hoop between the children to get from one end to the other in case of being in rows, and if it is in a circle that reaches the beginning where it began.

B. Rules: They must pass the hoop through the body without letting go of their hands. The team that first manages to pass the hoop among all the participants wins.

It is necessary to emphasize that in the organization and execution of the physical-recreational games it was not necessary that all the participants were in the teams, since the children repeated the actions of the game, in case their team was incomplete, since the proposed objective was to participate and complete all the proposed games. After applying the physical-recreational games, the evaluations issued by the participants were collected where they expressed the Positive, Negative and Interesting (PNI) of the games performed, in addition to observing the increase in participation, since the attendance ranged between 27 - 28 children for $96.5 \%$, being evaluated very well where they raised how good they felt, the desire to continue playing, since many of the proposed games did not know them and others had done them in physical education classes, but in previous degrees, they also recognized the benefits of performing active games, observing the acceptance and impact of physical-recreational games, before the activities they carried out in their free time, as being most of their time dependent on new technologies, all this influenced the good organization of the areas, the creative use of media, the selection of new physicalrecreational games, according to the tastes and preferences of the children. During the practice of physical-recreational games, the children showed interest in the creation of variants, strengthening the educational work through the opportunities they had to express freely, creatively and voluntarily their criteria to express how they would like to perform the games, in addition there was a great enthusiasm on the part of the relatives, community managers, as well as teachers, in the dissemination and execution of physicalrecreational activities.

1. The motivated, active and conscious participation of the children was achieved under the principle of voluntariness, where they were managers, actors and protagonists of the physical-recreational games they executed.

2. The girls suggested holding traditional costume parties, modeling and games which were supported by the parents. Most of the children did not have absences, indicating the satisfactory participation in the planned physical-recreational games, which managed to motivate its participants.

3. It is necessary to emphasize that in the execution of some physical-recreational games the children played with their relatives, where they demonstrated their experiences by stating that they "revived their childhood".

4. The motivation for the realization of the physical-recreational games selected from the interest shown by the children, were supported by the relatives and neighbors of the community.

5. The execution of the physical-recreational games allowed to be more united, both with the children of the same sex, as well as the interaction with those of the opposite sex, which helped to develop traits such as tolerance, consideration and mutual respect attending to the individual possibilities of each one and in a general sense group work was favored.

6. The participation of the children in the different physicalrecreational games contributed to the formation of knowledge, habits, sports skills and the development of values.

\section{Conclusion}

In the diagnosis carried out, it was found that the participation of children aged 9-12 years of the constituency \# 9, of the Bengochea Distribution, in the physical-recreational activities, was limited since they preferred to participate in other activities. The physical-recreational games were selected from a collective construction, taking into account the interests, tastes and preferences of the children of 9-12 years of the circumscription \# 9, of the Bengochea Distribution, which increased the participation to the physical-recreational activities. The participation in the activities, from the application of the physical-recreational games caused an atmosphere of socialization among the children, relatives, and other members of the community, where all the participants intervened, opined and supported, being the main managers, actors and protagonists.

\section{Recommendation}

Generalize this experience to increase participation towards the practice of physical-recreational activities in other age groups in the community.

\section{Conflict of Interest}

No conflict of interest with any institution/organization. 


\section{References}

1. Sosa A (2000) Hacia el necesario tránsito del consumismo al protagonismo como concepción de la recreación. (tesis doctorado). Instituto Superior de Cultura Física "Manuel Fajardo", La Habana, p. 55.

2. Pérez A (2010) Recreación: Fundamentos-Teóricos. La Habana. Cuba. Ed. Juan Marinello, p. 94.

3. Waichman P (2009) Cuál recreación para América Latina? Recuperado de.

4. Domínguez A (2018) Estrategia metodológica para la labor educativa de los docentes de la disciplina Recreación Física en la carrera de Cultura Física. (tesis de doctorado). Facultad de Cultura Física Universidad Central "Marta Abreu" de Las Villas.

5. Vilaú A, Rodríguez L, Rivera R, Amarán E (2012) Plan de actividades físico-recreativas para ocupar el tiempo libre en jóvenes desvinculados del estudio y el trabajo. Ciencias Médicas 16(3).

ISSN: 2574-1241

DOI: 10.26717/BJSTR.2021.40.006390

Rosa de la Cruz Hernández Moya. Biomed J Sci \& Tech Res

(c) (9) This work is licensed under Creative

Submission Link: https://biomedres.us/submit-manuscript.php
6. Espinosa A (2015) Plan de actividades físico-recreativas dirigidas al incremento de la participación de los niños entre 5 y 9 años de la comunidad Luis Lara. (tesis de pregrado). Facultad de Cultura Física Universidad Central "Marta Abreu” de Las Villas, p. 28.

7. Yanez Y (2017) Estrategia para el desarrollo sostenible de la recreación física en los espacios naturales del Litoral Norte de Mayabeque. (tesis de doctorado). Instituto Superior de Cultura Física "Manuel Fajardo", La Habana.

8. Rodríguez E, Oliveira B, Navarro R (2019) Análisis de las prácticas lúdicas y tradicionales en la zona norte del Camino Central Portugués y su relación con el ámbito educativo. Retos: nuevas tendencias en educación física, deporte y recreación 35: 25-30.

9. Hernández R, Fernández C, Baptista P (1992) Metodología de la investigación. Naucalpan de Juárez, Edo. de México: McGraw - Hill Interamericana de México.

10. Watson H (2008) Teoría y Práctica de los Juegos. La Habana, Cuba: Deportes, pp. 191.

$\begin{array}{ll}\text { BIOMEDICAL } & \text { Assets of Publishing with us } \\ \text { RESEARCHES } & \text { - Global archiving of articles } \\ \text { - Immediate, unrestricted online access } & \text { - Rigorous Peer Review Process } \\ & \text { - Authors Retain Copyrights } \\ & \end{array}$

